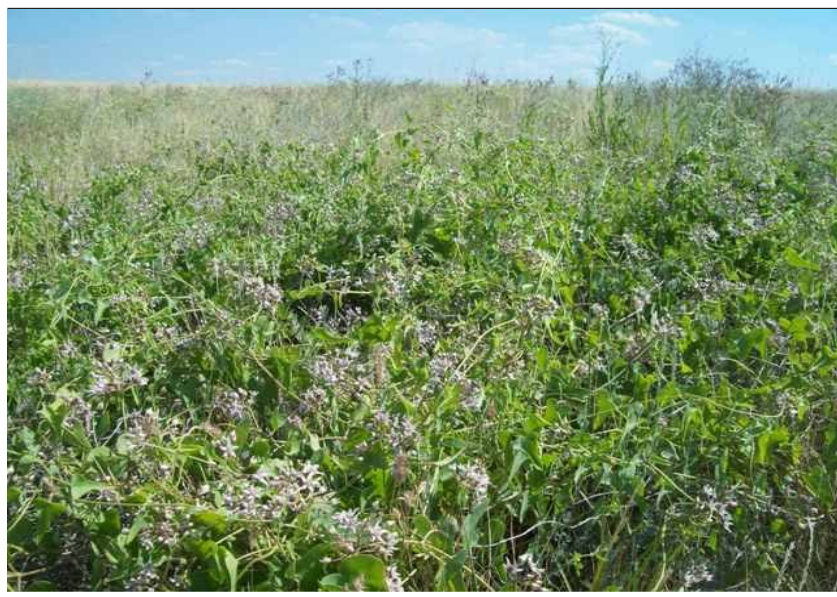

Рисунок 4 - Cynanchum acutum

7) Заволжье, Самарская обл., Синий Сырт Большечерниговский $\mathrm{p}$ - н, близ a/д между с. Красноокрябрьское и с. Кинзягулово, степные солонцеватые склоны и небольшие содовые солончаки, посадки карагача, 3.VII.2014, В.В., А.И., Т.Л.

Koeleria transvolgensis Tzvelev-KKCO $(+)$

Allium tulipifolium Ledeb.-KKCO $(+)$

Camphorosma monspeliaca L.-KKCO

Melilotus wolgicus Poir.

Veronica bashkiriensis (Klokov ex Tzvelev) Vasjukov

Galium tomentellum Klokov

Artemisia nitrosa Weber ex Stechm.

Crepis pannonica (Jacq.) K. Koch

Lactuca saligna L.

Saussurea salsa Spreng.
8) Заволжье, Самарская обл., Нефтегорский $\mathrm{p}$ - н, между с. Бариновка и с. Утевка, степные (залежные) склоны в правобережной части речки, впадающей в р. Самара, 3.VII.2014, В.В., А.И., Т.Л.

Astragalus cornutus Pall.-KKCO

Astragalus sulcatus L.-KKCO

Palimbia turgaica Lipsky-KKCO

Рекомендованы для включения в новое издание Красной книги Самарской области: Allium tulipifolium, Cynanchum acutum, Elaeosticta lutea, Euphorbia rossica, Euphorbia rossica, Koeleria transvolgensis, Stemmacantha serratuloides, Tulipa scythica.

\section{СПИСОК ЛИТЕРАТУРЫ:}

1. Красная книга Российской Федерации (растения и грибы). М., 2008. 855 с.

2. Красная книга Самарской области. Т. 1. Редкие виды растений, лишайников и грибов. Тольятти, $2007.372 \mathrm{c}$

3. Плаксина Т.И. Редкие, исчезающие растения Самарской области. Самара, 1988. 278 с.

4. Плаксина Т.И. Конспект флоры Волго-Уральского региона. Самара, 2001. 388 с.

5. Саксонов С.В., Сенатор С.А. Путеводитель по Самарской флоре (1851-2011). Флора Волжского бассейна. Т. 1. Тольятти, 2012. 511 с.

6. Сухоруков А.П., Васюков В.М., Раков Н.С., Лысенко Т.М. Дополнение к флоре Самарской области // Фиторазнообразие Восточной Европы. 2013. Т. 7, №3. C. 77-92.

7. Устинова А.А., Ильина Н.С., Митрошенкова А.Е. и др. Сосудистые растения Самарской области. Самара, 2007. $400 \mathrm{c}$.

(C) 2015

\title{
ON THE FLORA OF SYRTOVOJE ZAVOLZHJE
}

V.M. Vasjukov, Candidate of Biological Sciences, researcher, Laboratory of the Phytodiversity Problems

A.V. Ivanova, Candidate of Biological Sciences, researcher, Laboratory of the Phytodiversity Problems

T.M. Lysenko, Doctor of Biological Sciences, senior researcher, Laboratory of the Phytodiversity Problems

Institute of Ecology of the Volga River Basin, Togliatti (Russia)

Annotation. As a result of the floristic studies in Syrtovoje Zavolzhje within the Samara region in 2014, we found interesting in the phyto-geographical and environmental value species and subspecies of plants, including new to the flora of the Samara region (Cotinus coggygria (ergaziofit), Cynanchum acutum, Otites sibiricus subsp. kleopovii), species of the Red Book of the Russian Federation (Eriosynaphe longifolia, Iris pumila, Koeleria sclerophylla, Stipa pennata, Stipa pulcherrima, Tulipa schrenkii), species of the Red Book of Samara region (Astragalus cornutus, Astragalus macropus, Astragalus sulcatus, Atraphaxis frutescens, Camphorosma monspeliaca, Chrysocyathus volgensis, Dianthus leptopetalus, Ephedra distachya, Eremogone koriniana, Eriosynaphe longifolia, Ferula caspica, Ferula tatarica, Galatella angustissima, Goniolimon elatum, Iris pseudacorus, Iris pumila, Jurinea multiflora, Koeleria sclerophylla, Nepeta ucranica, Ornithogalum fischerianum, Palimbia turgaica, Plantago maxima, Stipa pennata, Stipa pulcherrima, Trinia hispida, Tulipa schrenkii). We recommend for inclusion in the new edition of the Red Book of Samara region the next species: Allium tulipifolium, Cynanchum acutum, Elaeosticta lutea, Euphorbia rossica, Euphorbia rossica, Koeleria transvolgensis, Stemmacantha serratuloides, Tulipa scythica.

Keywords: flora; rare species; Red Book; Samara region; Syrtovoje Zavolzhje.

УДК 598.243.8

\section{ОПЫТ ОПРЕДЕЛЕНИЯ ПОЛА ЛЮРИКОВ (ALLE ALLE LINK)}

(C) 2015 ПО ОЧЕРТАНИЯМ КЛЮВА
А.А. Виноградов, старший преподаватель кафедры биологии

Тверской государственныи университет, Тверь (Россия)

\footnotetext{
Аннотация. Разработанный нами ранее метод прижизненного, бесконтактного, полевого определения пола мономорфных птиц на примере белокрылой крачки, основанный на выявлении половых различий формы клювов противоположных полов по фотографиям оказался эффективным для идентификации пола у люриков (Alle alle). B графическом редакторе Photoshop SC2 нами были изготовлены усреднённые абрисы голов противоположных полов по совокупности абрисов с профильных крупномасштабных фотографий птиц, взятых из сети Интернет. Привязка к полу осуществлялась по фотографиям спаривающихся люриков. По результатам наших исследований были определены типы клюва самца и самки люриков и размерные параметры для их математического и статистического анализа. Статистически достоверными критериями отличия самца от самки являются высота надклювья и 47 Самарский научный вестник. 2015. № 2(11)
} 
подклювья на уровне границы оперения в подбородочной зоне и в середине клюва. Однако, эти параметры не могут рассматриваться как диагностические, т.к. обнаруживают существенные зоны перекрывания абсолютных значений признаков. Диагностическими же следует считать отношения (индексы) высот надклювья и подклювья, а также значения дискриминантных функций попарных соотношений указанных размерных параметров и индексов. В качестве проверки метода нами были проанализированы фотографии 49 люриков, достоверно известных по полу экзаменующей стороне, но не нам. В графическом редакторе на предложенные профильные фотографии люриков поочерёдно накладывались шаблоны усреднённых абрисов полов. Максимальное совпадение шаблона с очертаниями профиля птицы при вращении и трансформировании с сохранением пропорций являлось критерием её половой принадлежности. Пол всех люриков был определён нами верно. Наш метод позволяет безошибочно определять пол не только мономорфных видов птиц, но также диморфных видов во внебрачный период, молодых птиц и гнездовых птенцов. В настоящее время в разной степени детальности нами проанализированы около 570 видов птиц, и у всех них выявлен, в той или иной степени выраженный, половой диморфизм формы клюва.

Ключевые слова: мономорфные виды; люрик; профильные фотографии; абрисы; форма клюва; морфометрия; определение пола; дискриминантные функции.

Определение пола мономорфных видов птиц, и в частности группы морских птиц дистанционно и бесконтактно, в настоящий момент возможно лишь по результатам наблюдений их в брачный период или контактными способами по результатам промеров различных частей тела и оперения [1], осмотру формы клоакального выступа [2], по результатам вскрытия или ДНК-анализу. Последние способы определения пола возможны лишь при отлове или добыче птицы, но даже в этих случаях не всегда удается правильно идентифицировать пол. Несмотря на серию попыток $[3,4,5,6]$, эффективного метода бесконтактного определения пола мономорфных видов разработано не было. В последнее время для идентификации пола птиц различных видов наиболее активно используется дискриминантный анализ по парам или группам признаков. Так, например, для клушицы удалось добиться $100 \%$ точности разделения полов по длине цевки и ширине клюва [7], для такахе-85\% по длине надклювья и цевки [8], для пингвинов Адели 83.2-96.7\% успеха по длине и высоте клюва [9], для краснохвостых канюков-98\% для взрослых и 97\% для молодых по весу тела, длинам заднего пальца, цевки, хвоста, крыла и надклювья [10]. Подобные результаты дискриминантного анализа были получены по различным параметрам для других видов птиц $[11,12,13,14$ и др.]. Для дальневосточного аиста по фотографиям птиц удалось добиться $82 \%$ успеха по значениям дискриминантной функции выписанной по расстояниям от кончика клюва до затылка и до угла разреза рта [15].

1. Разработанный нами ранее метод выявления половых различий мономорфных видов птиц по очертаниям клюва по ряду его промеров и их соотношениям позволяет достоверно определять пол большинства видов птиц $[16,17,18,19,20,21]$. Настоящее исследование посвящено применению этого метода к определению пола люрика (Alle alle).

2. На предварительном этапе исследований в сети Интернет нами были отобраны крупномасштабные профильные фотографии 36 люриков достаточного качества для их анализа в графическом редакторе. Особое внимание было уделено профильным фотографиям спаривающихся птиц (8 пар). Абрисы головы каждого изображения пернатых

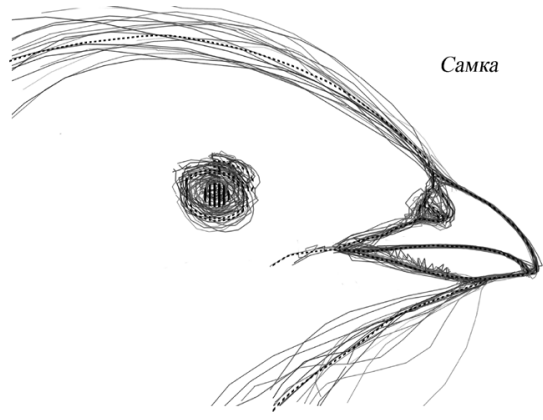

Рисунок 1 - Векторные контуры и усреднённый абрис самки люрика $(n=18$ экземпляров)

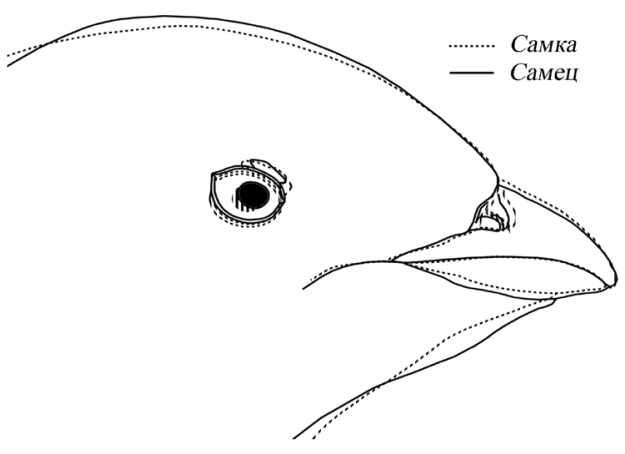

Рисунок 2 - Усредненные абрисы голов самича и самки люриков.

прорисовывались в программе Adobe Photoshop CS2 в прозрачных слоях. Полученные абрисы по возможности максимально точно совмещались друг с другом в одном произвольном масштабе с сохранением пропорций. В качестве реперных зон использовались: линия смыкания надклювья и подклювья, внешние границы надклювья и подклювья, границы оперения в области переносицы и подбородочной зоне, контуры ноздри, а также положение глаза. За исходные абрисы противоположных полов принимались контурные векторные рисунки, выполненные с изображений спаривающихся птиц. Для каждого пола по методу наименьших квадратов прорисовывался усреднённый абрис-образ (рис.1). Эти усреднённые абрисы-образы голов противоположных полов по возможности, максимально точно подгонялись друг к другу с сохранением пропорций (рис. 2). Выявленные таким образом различия формы клюва самцов и самок позволили выделить наиболее значимые промеры (рис. 3) для последующего математического и статистического анализа и характеризуют типы клюва самца и самки. Для установления половых различий формы клюва самцов и самок люриков нами использовались индексы: a/b-относительная мощность надклювья и подклювья в области границы оперения горла; d/с-относительная мощность надклювья и подклювья в середине клюва. Измерение параметров осуществлялось в графическом редакторе Photoshop SC2 9.0 в условных единицах (см). Всего нами было изготовлено 18 абрисов голов самцов и 18-самок.

Размерные данные заносились в таблицу Excel 2003, в которой анализировались зоны перекрывания абсолютных значений всех параметров и индексов для противоположных полов, и оценивалась точность разделения самцов и самок как процент от их количества. 


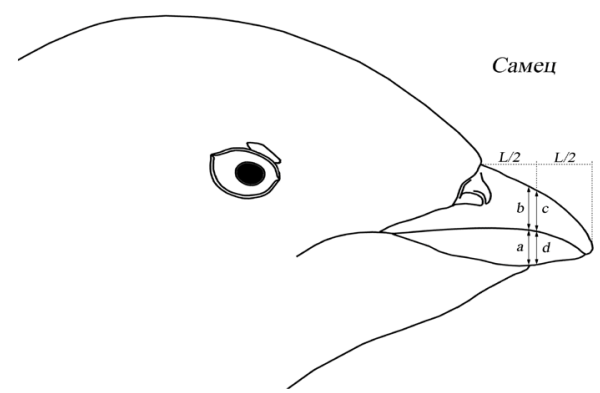

Рисунок 3 - Промеры клюва люриков: $а$-от смыкания клюва до нижнего края подклювья 6 области границы оперения горла, $b$-от конька до смыкания клюва в области границы оперения горла, cот конька до смыкания клюва в середине клюва, $d$-от смыкания клюва до нижнего края подклювья в середине клюва. L-длина клюва от границы оперения лба до вериины клюва.

В дополнение строились графики значений размерных параметров и их соотношений для самцов и самок люриков и выписывались уравнения прямых дискриминантных функций, разделяющих точки описанных выше параметров и соотношений Линия раздела значений параметров и соотношений вычерчивалась по двум точкам, каждая из которых рассчитывалась как средняя пары максимально сближенных на графике значений для самца и самки. Достоверность половых различий в форме клюва люриков по абсолютным значениям размерных и индексных признаков рассчитывалась по U-критерию Манна-Уитни и $\mathrm{t}$-тесту Стьюдента в программе STATISTICA 6 и Microsoft®Office Excel 2003, соответственно.

Для проверки изготовленных нами шаблонов усреднённых абрисов голов самца и самки люриков было проведено их тестирование на профильных фотографиях 49 птиц, достоверно определённых по полу.

Применение разработанного нами метода позволило охарактеризовать основные особенности в очертании клюва самца и самки люрика (рис. 2).

Тип клюва самки. Клюв выглядит заострённым и грацильным, несмотря на более высокое надклювье в основании. Подклювье заметно слабее надклювья и в области границы оперения в подбородочной зоне составляет около 0,60 от высоты надклювья.

Тип клюва самца. Клюв выглядит более робустным, несмотря на меньшую высоту надклювья в основании

Значения размерных параметров и индексов абрисов голов самиов $(n=18)$ и самок $(n=18)$ люриков, выполненных в одинаковом произвольном масштабе (сами̧ь в масштабе самок).

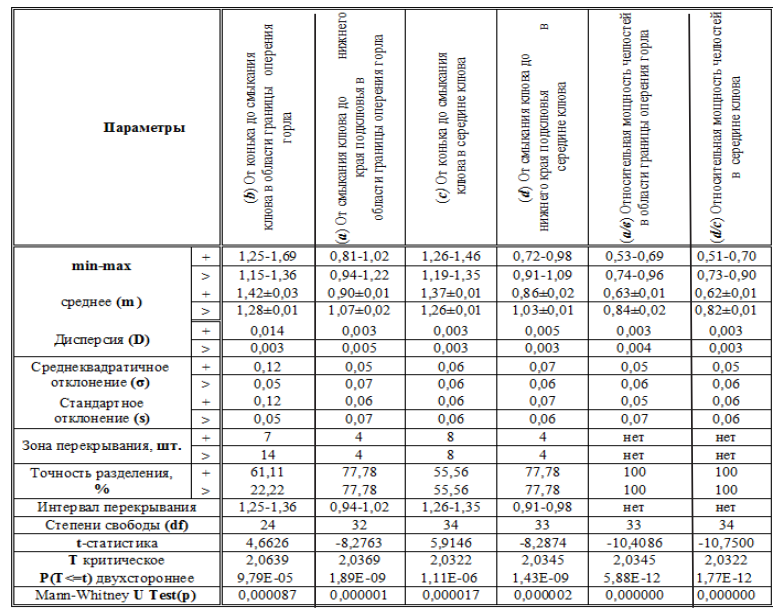

за счёт меньшей заострённости и более мощного подклювья. Отношение его высоты к высоте надклювья в области границы оперения в подбородочной зоне составляет более 0,80 .

Значения размерных параметров и их соотношений абрисов клювов люриков в графическом редакторе Photoshop SC2 9.0 в равном произвольном масштабе и условных единицах (см), а также их анализ, представлены в табл. 1.

Из неё видно, что по всем параметрам у самцов и самок имеются существенные зоны перекрывания значений от 4 для параметров а и d, до 14 для параметра b для самцов, и от 4 по параметрам а и d до 8 по параметру с для самок. Точность разделения полов по абсолютным значениям составляет для самок от $61,11 \%$ по параметру b, до 77,78\% по параметрам a и d, a для самцов от 22,22\% по параметру b до 77,78\% по параметрам a и d. Однако, несмотря на низкую точность разделения полов по абсолютным значениям признаков, статистическая достоверность возможности разделения полов по представленным параметрам высока.

По индексам $\mathrm{a} / \mathrm{b}$ и $\mathrm{d} / \mathrm{c}$ нет зон перекрывания значений для самцов и самок, точность разделения противоположных полов по ним составляет 100\%. Очевидно, что по абсолютным значениям этих соотношений возможно достоверно дифференцировать пол люриков, что хорошо просматривается и на представленной выше сравнительной схеме (рис. 2).

Наилучшие результаты дифференциации полов у люриков были получены нами при построении графиков значений параметров и выписывания уравнений прямым дискриминантных функций, полностью разделяющих самцов и самок для каждой пары (рис. $4,5,6$ ). Оказалось, что координаты парных значений параметров a и b, c и $\mathrm{d}$ и индексов $\mathrm{a} / \mathrm{b}$ и $\mathrm{d} / \mathrm{c}$ не перекрываются своими массивами ни на одном из построенных нами графиков зависимостей.

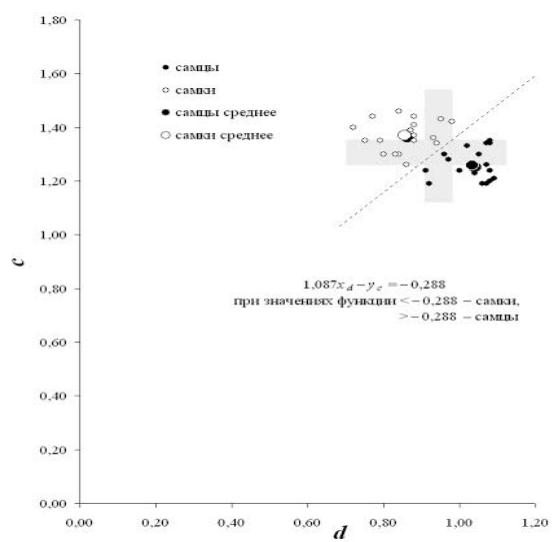

Рисунок 4 - Зависимость значений параметров $a, b$ для абрисов голов люриков, выполненных в одном произвольном масштабе (серый фон-зоньы перекрывания абсолютных значений признака).

Значения функций уравнений прямых, разделяющих эти массивы для соответствующих параметров противоположных полов, являются точной границей разделения самцов и самок люриков.

Для проверки возможности определения пола люриков мы воспользовались любезным предложением ведущего научного сотрудника Института проблем экологии и эволюции им. А.Н. Северцова РАН С.П. Харитонова, который предложил апробировать наш метод на авторских фотографиях люриков, достоверно определённых им по полу по результатам наблюдений в брачный период. Он передал нам профильные фотографии 49 люриков, 40 из которых были помечены цветными пластиковыми и металлическими кольцами. 


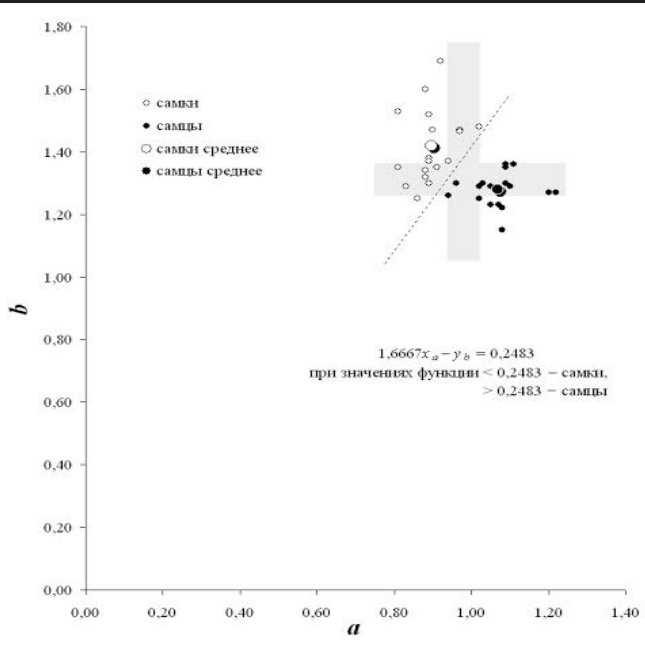

Рисунок 5 - Зависимость значений параметров $d, c$ для абрисов голов люриков, выполненных в одном произвольном масштабе (серый фон-зоны перекрывания абсолютных значений признака),

Информацией о половой принадлежности птиц мы не располагали. Используя наши шаблоны усреднённых абрисов противоположных полов люриков, нам удалось точно разделить по полу всех предложенных люриков с помощью описанного метода.

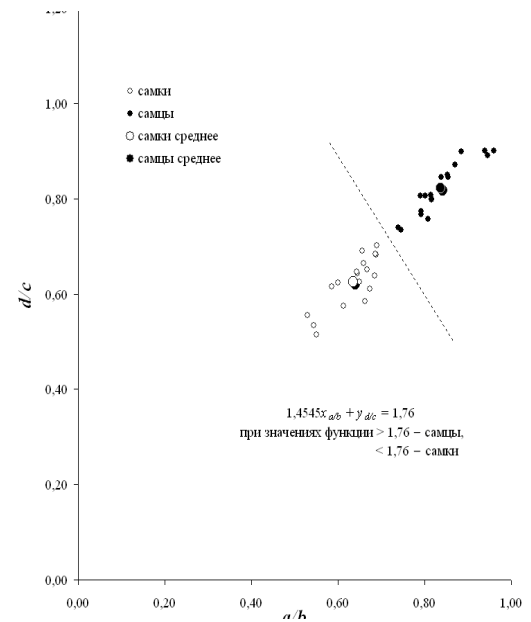

Рисунок 6 - Зависимость значений индексов $d / c$ и a/b абрисов голов люриков.

Таким образом, ранее разработанный нами метод дистанционного определения пола птиц по форме клюва, примененный к люрику, показал свою эффективность. Найденные визуальные различия в форме клюва между самцом и самкой подтверждаются статистически и позволяют определять пол птиц по фотографиям, а также при определённом навыке и на расстоянии в поле. Наш метод позволяет безошибочно определять пол не только мономорфных видов птиц, но также диморфных видов во внебрачный период молодых птиц и гнездовых птенцов. В настоящее время в разной степени детальности нами проанализированы 538 видов птиц, и у всех них выявлен в той или иной степени выраженный половой диморфизм в строении клюва.

\section{СПИСОК ЛИТЕРАТУРЫ}

1.Кречетов Ю.Н. Новый метод прижизненного определения пола у серых ворон. // Орнитология, №16, 1981. С. 173.

2.Boersma P.D., Davies E.M. Sexing Monomorphic Birds by Vent Measurements. // Auk. V. 104. 1987. P.779- 783.

3. Williams G.R., Miers K.H. 1958. A field method of sexing the swamphen or pukeko // Emu. V. 58. P. 125-127.

4. Anderson A. A method of sexing Moorhens // Wildfowl. V. 26. 1975. P. 77-82.

5. Fox G.A., Cooper C.R., Ryder J.P. Predicting the sex of herring gulls by using external measurements // Journal of
Field Ornithology. V. 52(1). 1981. P. 1-9.

6. Виноградова Н. В., Дольник В.Р., Ефремов В.Д., Паевский В.А. Определение пола и возраста воробьиных птиц фауны СССР. Справочник. М. «Наука», 1976. 189 с.

7. Blanco G. Age and sex determination of monomorphic non-breeding choughs: a long-term study // Journal of Field Ornithol., V. 67(3). 1996. P. 428-433.

8. Eason D. A comparison of five methods for assignment of sex in the takahe (Aves: Porphyrio mantelli). // J. Zool., Lond. 253. 2001. P. 281-292.

9. Polito M. J., Clucas G. V., Hart T., Trivelpiece W.Z. A simplified method of determining the sex of Pygoscelis penguins using bill measurements // Marine Ornithology. V.40(2). 2012. P. 89-94.

10. Donohue K.,C., Dufty A. Sex determination of Red-tailed Hawks (Buteo jamaicensis calurus) using DNA analysis and morphometrics. // Journal of Field Ornithology. V. 77(1). M., 2006. P. 74-79.

11. Jakubas A., Wojczulanis K. Predicting the sex of Dovekies by discriminant analysis // Waterbirds. V. 30(1). 2007. P. 92-96.

12. Cwiertnia P., KwiecińskiZ., Kwiecińska, Wysocki A., Tryjanowski P., Ollson O. Sexing of white storks Ciconia ciconia based on biometric measurements. / Tryjanowski P., Sparks T.H., Jerzak L. (eds.) "White stork study in Poland: biology, ecology and conservation". Bogucki Wydawnictwo Naukowe, Poznań. 2006. P. 123-129.

13. Hammouda A., Selmi S. Morphometric sexing of Mediterranean Yellow-legged Gulls Larus michahellis michahellis breeding in the Gulf of Gabès, southern Tunisia. / Ostrich. V. 84(2). 2013. P. 119-122.

14. Craig G.L., Mcardle B.H., Wettin P.D. Sex determination of the pukeko or purple swamphen // Notornis., V. 27. 1980. P. 287-291.

15. Cheong S., Sung H-C., Park S-R. A new method for sexing Oriental White Storks // Journal of Field Ornithology. V. 78(3). 2007. P. 329-333.

16. Виноградов А.А., Зиновьев А.В. Предварительное сообщение об адаптивности половых различий формы клюва у двух видов ястребиных с комментариями по эволюции обратного полового диморфизма у птиц/Труды VI Международной конференции по соколообразным и совам Северной Евразии «Хищные птицы в динамической среде третьего тысячелетия: состояние и перспективы». Криворожский педагогический институт. Кривой Рог: Издатель ФЛ-П Чернявский Д.А. 2012. C.61-64.

17. Vinogradov A.A. Bill shape helps in non-invasive determination of sex in monomorphic White-winged Tern (Chlidonias leucopterus, Sternidae, Aves) / ed. Haim A. Zoology in a changing world. How animals respond to human activities. Proceedings of the XXI International Congress of Zoology. University of Haifa. Haifa: 2012. P.119.

18. Виноградов А.А. Метод выявления половых различий в строении клюва мономорфных видов птиц: на примере белокрылой крачки (Chlidonias leucopterus , Sterninae) // Зоологический журнал, том 93, №10. 2014. C. $1236-1249$.

19. Zinoviev A.V., Vinogradov A.A. Morphoecological explanations of sexual differenced in bill shape of bowerbirds (Ptylorhynchidae: Passeriformes) Ornithological Science. V. 13. Suppl., 2014. P. 09-024.

20. Виноградов А.А. Метод бесконтактного определения пола птиц: возможности и достоинства // Вестник ТвГУ. Серия «Биология и экология», №4. 2014. C. $30-44$.

21. Виноградов А.А. Половые различия в строении клюва птиц на примере белого аиста (Ciconia Ciconia L.) / Редкие виды птиц Нечернозёмного центра России. Материалы V совещания «Распространение и экология редких видов птиц Нечерноземного центра России» (Москва, 6-7 декабря 2014). 2014. С. 163-170. 


\title{
AN EXPIENCE OF THE LITTLE AUK SEXING (ALLE ALLE LINK)
}

(C) 2015 BY THE BEAK OUTLINES

\author{
A.A. Vinogradov, Assistant Professor, Biology Department \\ Tver State University, Tver (Russia)
}

Annotation. The method of the distant field sexing of the monomorphic birds by the photographs developed initially for the White-winged Tern (Chlidonias leucopterus), turned out to be effective for the monomorphic little auks (Alle alle). Outlines of head and beak of "average" male and female have been prepared with an aid of Photoshop SC2 from the multiple individual outlines, based on a number of photographs of the birds of know sex (copulating birds), taken from the Internet. Males statistically significant differ from females by the heights of maxilla and mandible at the border of feathers and in the middle of the beak. However, heights cannot be treated as diagnostic due to the extensive zones of overlapping. The truly diagnostic criteria are the ratios (indexes) of the height to each other as well as the values of the discriminant functions of the mentioned ratios. Acquired thus outlines and ratios have been applied to the 49 individuals of the little auks on the photographs. Their sex was known to the examining party, but not to the author. The maximal match of the outlines to the specimen on the photograph showed its possible sex. The subsequent check of the data showed $100 \%$ correct sexing. Similar level of the correct sexing has been reached by using the discriminant equations, based both on a number of measurements of the beak (significantly different in the opposite sexes) and the ratios between these measurements, showing the degree of their robustness and expression of certain characters of the beak (gonys, nail, culmen, etc.).

The mentioned method is useful not only for the monomorphic species of all the ages and in various seasons, but also for the dimorphic species in the periods, when distant sexing is difficult (non-breeding, juvenile and nestling plumage). About 570 species, studied so far, proved the sensitivity of the sexing method.

Keywords: monomorphic species; little auk; profile photographs; outlines; beak shape; morphometry; sexing; discriminant anaylisis.

УДК 581.9

\section{ЭКОЛОГИЧЕСКИЙ АНАЛИЗ ФЛОРЫ И РАСТИТЕЛЬНОСТИ ОКРЕСТНОСТЕЙ ЗАБРОШЕННОГО МЕЛОВОГО ДОБЫВАЮЩЕГО КАРЬЕРА У Р.П. СТАРАЯ КУЛАТКА (C) 2015 \\ Ульяновский государственный педагогический университет им. И.Н. Ульянова, Ульяновск (Россия)}

Аннотащия. В статье дается экологическая оценка флоры заброшенного мелового карьера, расположенного на северо-востоке р.П. Старая Кулатка Ульяновской области, ныне входящей территориально в состав ООПТ «Бахтеевские увалы». На основе разнообразных показателей дается анализ флоры: соотношение жизненных форм по системам К. Раункиера и И.Г. Серебрякова, экологический состав, эколого-ценотический анализ, кроме того, прослеживается динамика растительности и ее особенности при прекращении хозяйственной деятельности. Детальный анализ флоры показал эталонность данной некогда трансформированной человеком экосистемы и своевременность создания охраняемой территории, а также высокую способность растительности кальциевых ландшафтов к восстановлению.

Выявлены растительные сообщества, вмещающие такие охраняемые и редкие виды растений, как: Serratula gmelinii Tausch., Adonis vernalis L., Pulsatilla patens (L.)Mill. Последующего уточнения и подтверждения требует находка молодого растения Schivereckia podolica Andrz. Встречено карантинное заносное растениеCyclachaena xanthifolia (Nutt.) Fresch. и адвентивный вид Ceratocephala testiculata (Crantz) Besser-это новые точки распространения данных растений для Ульяновской области.

Территория заброшенного карьера по добыче мела может послужить площадкой для исследований естественного восстановления растительности после прекращения хозяйственной деятельности.

Ключевые слова: флора; биоморфы; антропогенная трансформация; редкие виды; адвентивные виды; воздействие добычи мела на окружающую среду.

Современный растительный покров комплексного ландшафтного заказника «Бахтеевские увалы», созданного в 2012 году, отличается относительно невысокой степенью антропогенной трансформации, что повышает его природоохранную ценность и экосистемную значимость [1, 2, 3, 4].

При этом различные участки заказника «Бахтеевские увалы» в разное время подвергались разным по своей интенсивности антропогенным нагрузкам. В этом отношении особый интерес представляет территория заброшенного мелового карьера на северо-востоке р.п. Старая Кулатка. Этот значительно трансформированный при хозяйственной деятельности участок интересен тем, что здесь можно проследить динамику восстановления растительности, состав и ее особенности при прекращении хозяйственной деятельности.

Известно, что мелодобывающее предприятие, принадлежавшее Старокулаткинскому району, не менее
25 лет назад добывало, дробило до различных фракций меловую породу для последующего хозяйственного применения. Писчий мел этого месторождения, помимо высокого качества, имеет богатую ископаемую фауну представленную беспозвоночными животными (иглокожие, двустворчатые и головоногие моллюски) и другими окаменелостями и отпечатками различных организмов $[5,6]$. При этом на площади 1,5-2 км2, в среднем, был снят 1-3 метровый слой дерново-карбонатной почвы и меловой породы. Вероятнее всего, до хозяйственного освоения здесь была тырсовая степь, которая сохранилась на меловых холмах, окружающих карьер.

В настоящее время растительные сообщества карьера находятся на разных стадиях своего восстановления. Центральные участки, больше всего подвергшиеся воздействию человека, находятся на инициальной стадии восстановления, с характерным для этого этапа 